\title{
Aspectos nutritivos de alguns peixes da Amazônia
}

\author{
Yolanda Rebêlo da Rocha ('); Jaime Paiva Lopes Aguiar ('); Helyde Albuquerque Marinho (') \\ e Roger Shrimpton (')
}

Resum:o

Onze espécies de peixes, os mais consumidos pela população de Manaus em 1973-74, foram analisados quanto aos seus conteúdos de: umidade, cinzas, proteina, goraura, energia e zinco. Os peixes carnıvoros como: Iucunaré, Hirarucu e a Pescada eram magros, enquanto $\mathrm{Pacu}$, Sardinha, Curimatã, Matrinchã e Branquinna toram considerados como gordos. Os peixes representavam aito teor protéıco, com razões proteina/ energıa muito além das recomendadas (FNB-USA). As razoes zinco/energia eram aitas somente nos peixes mienos goraurosos, ou nos peixes carnivoros como iucunare e rescada. Estes peixes sao coiocados entre os mass caros no mercado de Manaus. Os peixes herbıvoros e/ou onıvoros como Matrınchă, Curımata, iambayuı e branquınha apresentaram uma razảo zınco/energıa abaıo ao nivel recomenaaco. Discutem-se as possiveis importancias desses resultados.

\section{INTRODUÇÃo}

Em recente análise dos dados de um estudo sobre orçamencos familiares feitos em Manaus, em 1y/3-74 (Shrimpton \& Giugliano, 19/9; Shrimpton, 1980), usando-se valores de tabelas de composição de alimentos, apontouse a ingestão de zinco como a mais baixa entre dez nutrientes. É reconhecido que o uso de valores de composição obtidos da literatura pode ser causa de erro na avaliação de consumo de nutrientes (Stock \& Wheeler, 1972) e por isso é necessário proceder a análise dos alimentos locais. O consumo de peixe no Amazonas é alto (Honda, 1972), sendo sete vezes maior em Manaus do que em outras capitais brasileiras (Shrimpton \& Giugliano, 1979). Entretanto, poucos são os dados conhecidos referentes à composição química dos peixes da Amazônia, com nenhum estudo sobre o teor de zinco. O conhecimento da composiçẫo quím: ca do pescado "in natura" proporciona valiosos subsídios para melhorar a avaliação de consumo de nutrientes na aplicação dietética e dietoterápica. Considerando o papel importante do peixe na alimentação do amazonense, este trabalho propõe-se a analisar os mesmos, especialmente quanto aos seus conteúdos de energia, proteína e zinco e a relação com os níveis de ingesta recomendados para os mesmos.

\section{MATERIAL E MÉTODOS}

São estudadas neste trabalho apenas as onze espécies de peixes citadas como as mais consumidas pela população de Manaus em 1973-74 (Shrimpton \& Giugliano, 1979). Os peixes foram adquiridos diretamente no Mercado Municipal de Manaus para o laboratório de $\mathrm{Nu}$ trição do INPA, no mês de maio de 1978, onde foram tratados devidamente, Ihes sendo retiradas as vísceras, escamas e nadadeiras; a parte desperdiçada foi pesada e calculada. Para essa análise utilizaram-se dez peixes de cada espécie sempre que possível.

Toda vidraria usada foi cuidadosamente iavada em banho de ácido e água deionizada, para evitar contaminação das amostras por zinco.

As análises foram feitas do peixe inteiro, por que é adquirido e preparado para o consumo dessa maneira, desprezando-se apenas as visceras, nadadeiras e escamas. Posteriormente o peixe é "ticado" (cortado em fatias bem finas, incompletas, transversais, que se sucedem da extremidade do opérculo até o final da nadadeira caudal) com o objetivo de cortar em pedaços bem pequenos as espinhas encontradas ao longo do peixe, ficando inteiras somente as costelas e o espinhaço; facilitando-se assim um aproveitamento bem maior da carne do pescado, que pode ser cozido, frito ou assado.

(1) - Instituto Nacional de Pesquisas da Amazônia, Manaus, AM. 
As amostras foram secadas em estufa a $110^{\circ} \mathrm{C}$, até peso constante, para determinação de umidade. Depois de seca, a amostra foi macerada no gral e usada para as demais análises como segue: Proteínas - pelo processo de Kjeldahl (Horwitz, 1975); Gordura - por extração com éter de petróleo, em Soxhlet; Cinzas - na mufla, a $600^{\circ} \mathrm{C}$ (Horwitz, 1975). Todas as análises foram feitas com amostras triplicadas; Carboidrato total - foi calculado por diferença; Energia - foi calculada usando-se os fatores de conversão, sendo 4 calorias por grama de proteína, 9 calorias por grama de gordura e 4 calorias por grama de carboidrato.

A determinação de zinco foi feita usando método de Isaac \& Johnson (1975), na qual 1 grama de amostra seca foi colocado na estufa a $100^{\circ} \mathrm{C}$ até peso constante. $\mathrm{O}$ cadinho com a amostra foi aquecida a uma temperatuia de $500^{\circ} \mathrm{C}$ na mufla por uma noite. Depois de fria, foram adicionadas 10 gotas de água deionizada a $4 \mathrm{ml}$ de $\mathrm{HNO}_{3}(1: 1)$ e levada a banho de areia numa temperatura baixa, para evapuração de excesso de ácido nítrico e retornado a mufla por 1 hora, na mesma temperatura acima citada. Os resíduos de cinza foram dissolvidos com $10 \mathrm{ml} \mathrm{HCl}(1: 1)$ e transferidos quan. titativamente para um balão volumétrico de $100 \mathrm{ml}$ completando com $\mathrm{H}_{2} \mathrm{O}$ deionizada. O zinco foi determinado por meio de um espectrofotômetro de absorção atômica segundo re. comendações do fabricante (Perkin Elmer, 1976).

Os níveis de zinco, p:oteína, energia e gordura encontrados nos peixes foram correlacionados, usando anáiise de covariança (Armitage, 1971). A capacidade dos peixes para enriquecer as dietas para proteína e zinco foi feita comparando as razōes proteína/energia e zinco/energia encontradas nos peixes, com as ingestas recomendacias (FNB-USA, 1980), sendo $20 \mathrm{~g}$ proteína/1000 celorias e $50 \mathrm{mg}$ zin$\mathrm{co} / 1000$ calorias.

\section{RESUltados E DISCUSSÃo}

No Mercado Municipal de Manaus os peixes eram vendidos da seguinte maneira: Tucunaré, Pescada, Matrinchã @ Curimatã, eram vendidos por unidade, mas, o Pirarucu era vendido em quilos de filé. A Sardinha, Branquinha, Pacu, Aracu e Jaraquí, eram vendidos por "enfiada", ou seja, 5 peixes presos por uma tira de jauari; o Tambaqui era vendido inteiro ou aberto em bandas, sem vísceras e geralmente sem escamas.

A Tabela 1 apresenta o nome vulgar e científico de cada peixe, média do peso por unidade, peso máximo, tomando por base o número de amostras analisadas, e a porcentagem comestivel obtida tendo-se por base o peixe inteiro. O Tambaqui teve analisado uma banda de cada peixe, chegando a pesar cada banda até $3 \mathrm{~kg}$. Um Pirarucu inteiro pode pesar mais de $60 \mathrm{~kg}$, fornecendo aproximadamente $40 \mathrm{~kg}$ de carne, porém não conseguimos comprar peixes inteiros. Podemos notar que as espécies de maior aproveitamento foram: Pacu, Jaraqui, Tucunaré e Matrinchã. Sobre o Pirarucu, por não ter sido analisado o peixe inteiro, não podemos opinar neste aspecto.

São encontradas, na Tabela 2, o número de calorias fornecidas por $100 \mathrm{~g}$ de peixe analisado e os teores de umidade, proteína, gordura e cinzas. Foram de alto valor energético - Pacu, Sardinha, Curimatã e Matrinchä, enquanto que o Pirarucu, o Tucunaré e a Pescada apresentam baixo valor como está mostrado na figura 1. O teor energético mostrou uma correlação forte e significativa com o teor de gordura $(r=0.99 p<.01)$, (veja Fig. 1). Peixes são classificados como gordos quando contém um teor de gordura acima de $15 \%$, médios ou semi-gordos, quando variam entre 5 a $15 \%$ e magros quando abaixo de $5 \%$ (Stansby, 1961): De acordo com esta classificação, o Pacu, Sardinha, Curimatã, Matrinchã, Branquinha e os peixes onívoros ou herbívoros, podem ser considerados como gordos, a Pescada, Pirarucu e o Tucunaré como magros, e as outras espécies como semi-gordos.

Seria importante ressaltar que os peixes onívoros ou herbívoros, migradores, com desova total uma vez ao ano, como o Jaraqui e o Tambaqui por exemplo, têm alta variação de gordura entre os períodos de cheia e vazante. Esta variação é menor ou ausente nos peixes 


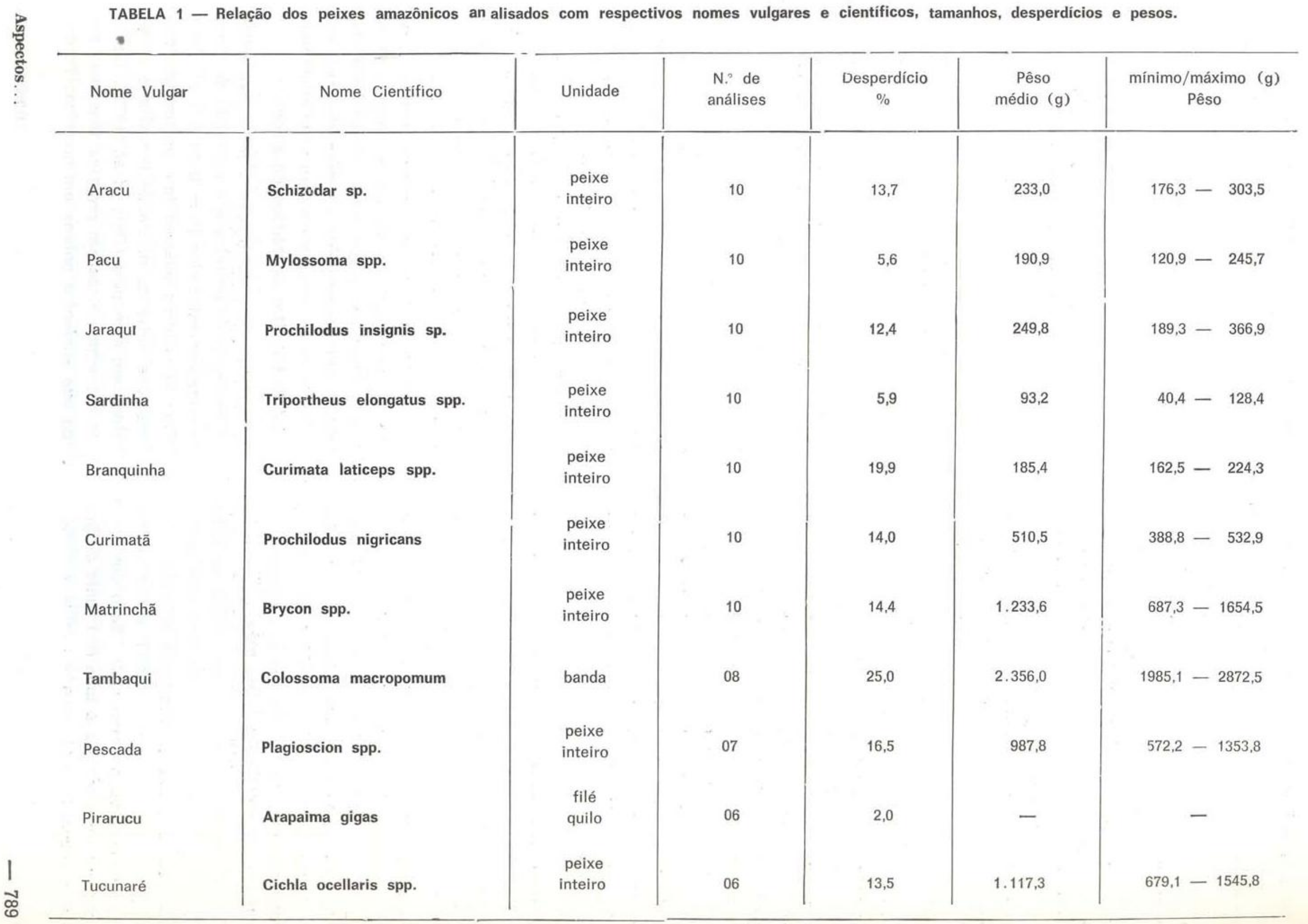


TABELA 2 - Composição de $100 \mathrm{~g}$ da parte comestivel de alguns peixes amazônicos, de proteína, gordura, umidade, zinco e energia.

\begin{tabular}{|c|c|c|c|c|c|c|c|}
\hline Nome Vulgar & Descriçẫo & $\begin{array}{c}\text { Energia } \\
\text { (Cal) }\end{array}$ & $\begin{array}{c}\text { Umidade } \\
\%\end{array}$ & $\begin{array}{l}\text { Proteína } \\
\text { (g) }\end{array}$ & $\begin{array}{l}\text { Gordura } \\
\text { (g) }\end{array}$ & $\begin{array}{c}\text { Cinzas } \\
\text { (g) }\end{array}$ & $\begin{array}{l}\text { Zinco } \\
(\mathrm{mg})\end{array}$ \\
\hline Aracu & $\begin{array}{l}\text { cru (filé) } \\
\text { cru (inteiro) }\end{array}$ & $\begin{array}{l}167,2 \\
159,3\end{array}$ & $\begin{array}{l}69,7 \\
69,2\end{array}$ & $\begin{array}{l}19,3 \\
18,0\end{array}$ & $\begin{array}{r}10,0 \\
9,7\end{array}$ & $\begin{array}{l}1,0 \\
3,1\end{array}$ & $\begin{array}{l}1,1 \\
1,3\end{array}$ \\
\hline Pacu & $\begin{array}{l}\text { cru (filé) } \\
\text { cru (inteiro) }\end{array}$ & $\begin{array}{l}145,2 \\
292,1\end{array}$ & $\begin{array}{l}71,5 \\
56,1\end{array}$ & $\begin{array}{l}18,3 \\
17,0\end{array}$ & $\begin{array}{r}8,0 \\
24,9\end{array}$ & $\begin{array}{l}2,2 \\
2,0\end{array}$ & $\begin{array}{l}0,8 \\
1,7\end{array}$ \\
\hline Jaraqui & $\begin{array}{l}\text { cru (filé) } \\
\text { cru (inteirn) }\end{array}$ & $\begin{array}{l}129,2 \\
121,2\end{array}$ & $\begin{array}{l}72,5 \\
67,0\end{array}$ & $\begin{array}{l}20,1 \\
18,6\end{array}$ & $\begin{array}{r}5,4 \\
11,4\end{array}$ & $\begin{array}{l}2,0 \\
3,0\end{array}$ & $\begin{array}{l}0,8 \\
1,2\end{array}$ \\
\hline Sardinha & $\begin{array}{l}\text { cru (filé) } \\
\text { cru (inteiro) }\end{array}$ & $\begin{array}{l}151,5 \\
260,3\end{array}$ & $\begin{array}{l}71,0 \\
58,5\end{array}$ & $\begin{array}{l}18,3 \\
18,5\end{array}$ & $\begin{array}{r}8,7 \\
20,7\end{array}$ & $\begin{array}{l}2,0 \\
2,0\end{array}$ & $\begin{array}{l}1,1 \\
2,2\end{array}$ \\
\hline Branquinha & $\begin{array}{l}\text { cru (filé) } \\
\text { cru (inteiro) }\end{array}$ & $\begin{array}{l}223,5 \\
217,2\end{array}$ & $\begin{array}{l}62,5 \\
64,2\end{array}$ & $\begin{array}{l}21,0 \\
17,4\end{array}$ & $\begin{array}{l}15,5 \\
16,4\end{array}$ & $\begin{array}{l}1,2 \\
2,0\end{array}$ & $\begin{array}{l}1,1 \\
2,0\end{array}$ \\
\hline Curimatã & $\begin{array}{l}\text { cru (filé) } \\
\text { cru (inteiro) }\end{array}$ & $\begin{array}{l}208,4 \\
250,7\end{array}$ & $\begin{array}{l}64,9 \\
62,0\end{array}$ & $\begin{array}{l}19,7 \\
16,1\end{array}$ & $\begin{array}{l}14,4 \\
20,7\end{array}$ & $\begin{array}{l}1,0 \\
1,2\end{array}$ & $\begin{array}{l}0,9 \\
1,2\end{array}$ \\
\hline Matrinchã & $\begin{array}{l}\text { cru (filé) } \\
\text { cru (inteiro) }\end{array}$ & $\begin{array}{l}187,8 \\
245,5\end{array}$ & $\begin{array}{l}66,8 \\
60,0\end{array}$ & $\begin{array}{l}20,4 \\
19,3\end{array}$ & $\begin{array}{l}11,8 \\
18,7\end{array}$ & $\begin{array}{l}1,0 \\
2,0\end{array}$ & $\begin{array}{l}0,9 \\
1,1\end{array}$ \\
\hline Tambaqui & $\begin{array}{l}\text { cru (filé) } \\
\text { cru (inteiro) }\end{array}$ & $\begin{array}{l}138,1 \\
151,4\end{array}$ & $\begin{array}{l}72,7 \\
66,3\end{array}$ & $\begin{array}{l}19,0 \\
24,8\end{array}$ & $\begin{array}{l}6,9 \\
5,8\end{array}$ & $\begin{array}{l}1,4 \\
3,1\end{array}$ & $\begin{array}{l}0,3 \\
0,6\end{array}$ \\
\hline Pescada & $\begin{array}{l}\text { cru (filé) } \\
\text { cru (inteiro) }\end{array}$ & $\begin{array}{l}89,3 \\
96,6\end{array}$ & $\begin{array}{l}77,5 \\
75,9\end{array}$ & $\begin{array}{l}19,4 \\
20,1\end{array}$ & $\begin{array}{l}1,3 \\
1,8\end{array}$ & $\begin{array}{l}1,8 \\
2,2\end{array}$ & $\begin{array}{l}0,9 \\
1,6\end{array}$ \\
\hline Pirarucu & cru (filé) & 120,7 & 73,2 & 20,5 & 4,3 & 2,0 & 0,5 \\
\hline Tucunaré & $\begin{array}{l}\text { cru (filé) } \\
\text { cru (inteiro) }\end{array}$ & $\begin{array}{l}102,3 \\
142,0\end{array}$ & $\begin{array}{l}76,0 \\
69,2\end{array}$ & $\begin{array}{l}20,4 \\
22,0\end{array}$ & $\begin{array}{l}2,3 \\
6,0\end{array}$ & $\begin{array}{l}1,3 \\
2,8\end{array}$ & $\begin{array}{l}1,2 \\
1,5\end{array}$ \\
\hline
\end{tabular}

carnivoros, os quais ocupam o fim da cadeia alimentar, não migram tanto e tem desova con. tínua. Os peixes, neste estudo, foram analisados no pico da cheia quando os peixes onívoros ou herbívoros estavam em fase de engorda em preparação para a desova no início da vazante no próximo mês.

Como pode ser esperado, todas as espécies aqui estudadas mostram alto teor protéico, pois apresentam resultados acima de $15 \mathrm{e}$ $20 \%$. Segundo Stansby (1961), esses valores são considelados como altos. Sem dúvida, o pescado da Amazônia é uma rica fonte de proteína animal.
Em média, os filés tinham menos zinco $(0.85 \mathrm{mg} / 100 \mathrm{~g})$ que nos peixes inteiros $(1.53$ $\mathrm{mg} / 100 \mathrm{~g}$ ). Isto pode estar associado à presença dos ossos ou de algumas vísceras nos últimos casos como o cérebro e/ou olhos. que podem ter altos conteúdos de zinco.

Houve uma correlação significativa entre o conteúdo de proteína e o conteúdo de zinco nos peixes estudados $(r=0.53 \mathrm{p} \mathrm{0.05)}$ (veja Fig. 2). Outros autores tem encontrado correlações entre os níveis de proteína e os de zinco em alimentos (Osis et al., 1972). De fato, alimentos ricos em proteína têm mais zinco que alimentos pobres em proteína. Porém, 


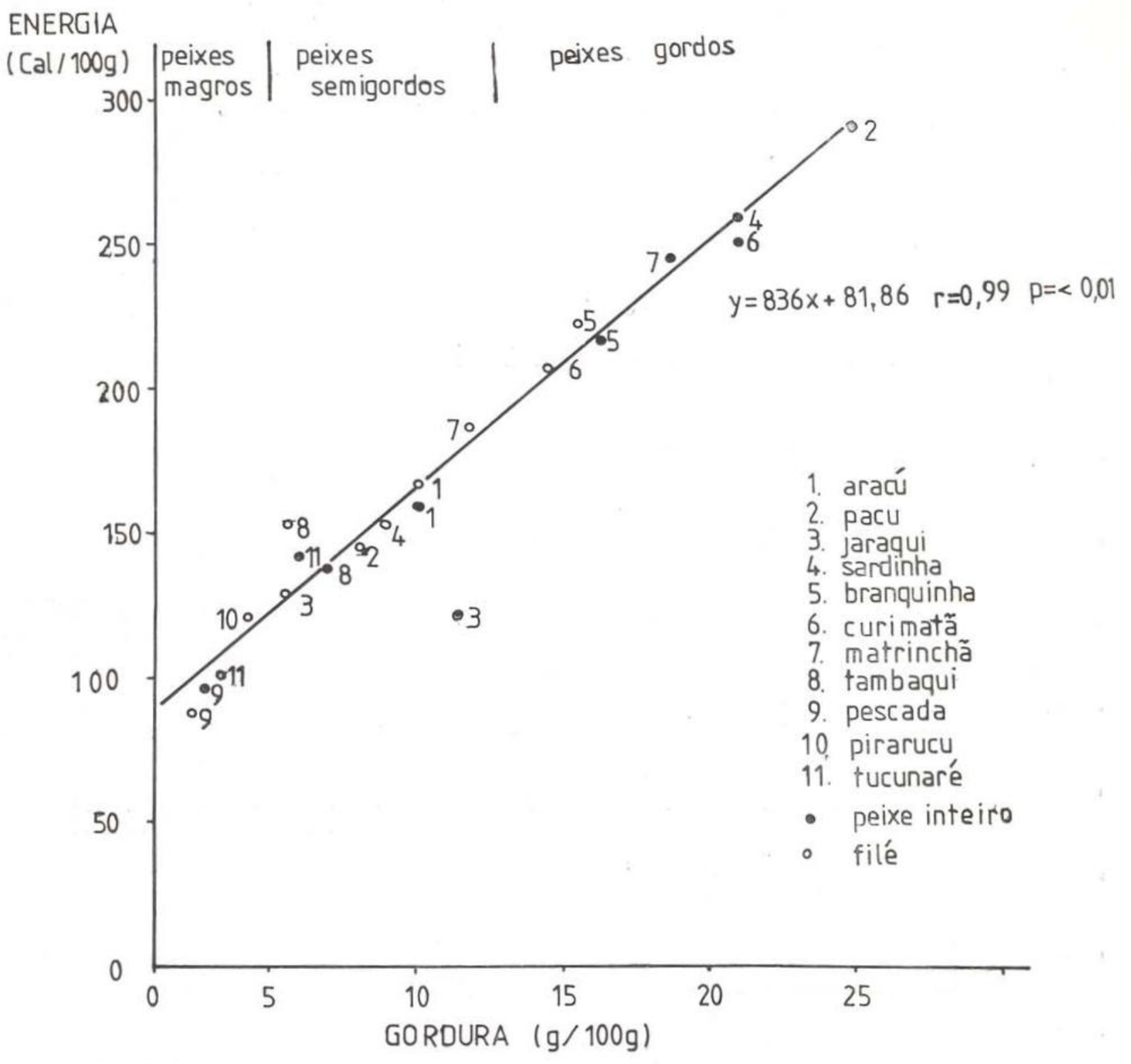

Fig. 1 - Relação entre conteúdo de gordura e energia em alguns peixes da Amazônia.

nos alimentos rịcos en proteína ainda se acha uma variação grande nas quantidades de zinco encontrado.

Comparando as razões zinco/energia e proteína/energia, observamos que os peixes são de fato excelentes fornecedores de proteína, produzindo 3 a dez vezes a razão proteína/energia necessária para poder enriquecer a dieta em proteína. Porém, quanto ao zinco. os peixes não são tão ricos. Quatro dos peixes, Matrinchã, Curimatã, Tambaqui (filé) e a Branquinha, mostraram uma razão zinco/ener- gia abaixo de $5 \mathrm{mg} / 1000$ calorias, podendo ser considerado como muito pobres em zinco (So. lomons \& Shrimpton, 1982).

Outros peixes eram intermediários $[5,10$ $\mathrm{mg} / 1000$ Cals), como Pacu, Pirarucu, Jaraqui, Aracu, Sardinha e Branquinha inteiros. Os peixes com altos teores de zinco por 1000 calorias são apenas, o Tucunaré e a Pescada. Ambos são os peixes de preços mais elevados e preferidos no mercado de Manaus, sendo o Tucunaré conhecido como o peixe dos reis (Araújo Lima, 1923). 


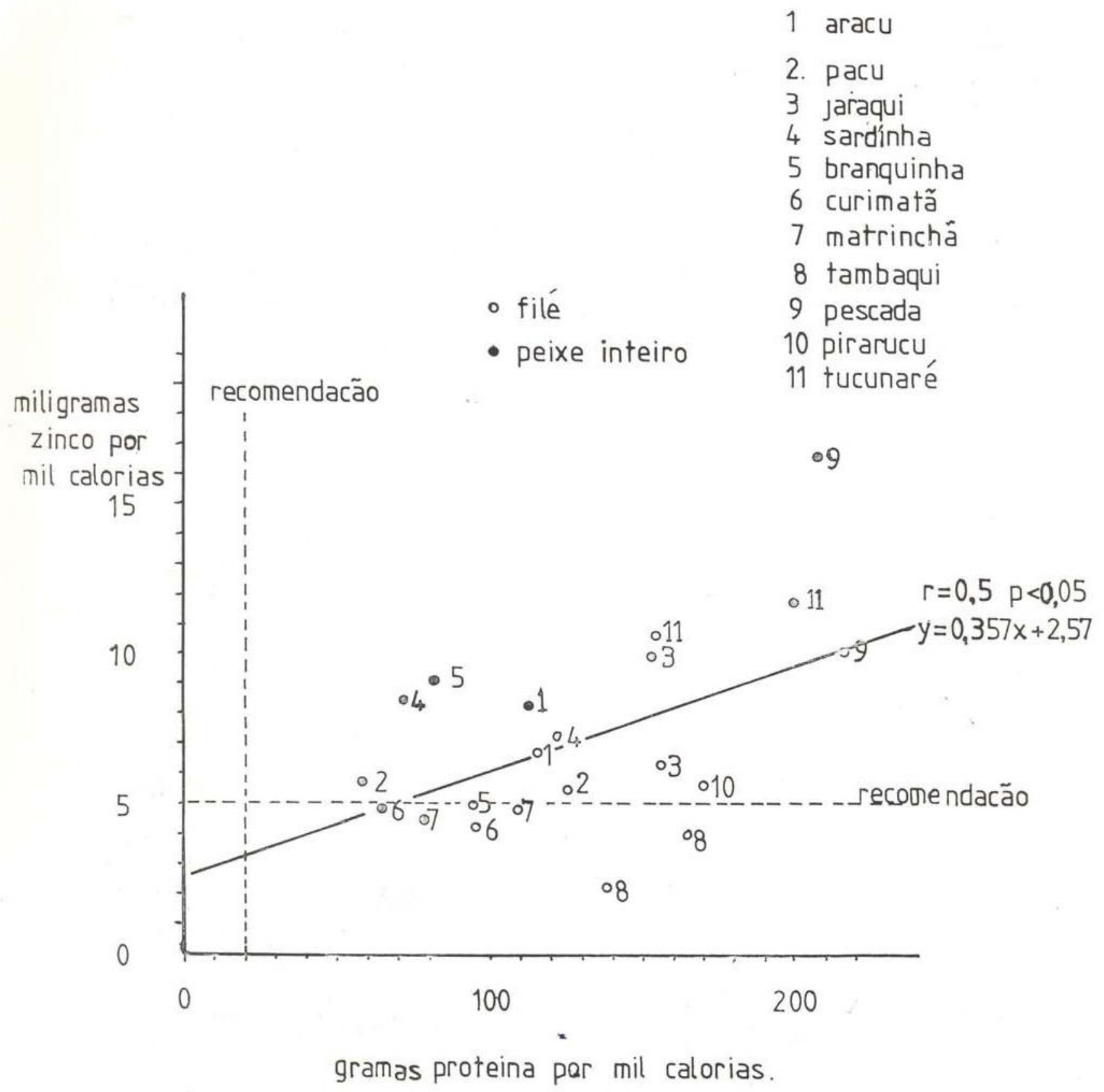

Fig. 2 - Relação entre as razões proteína/energia e zinco/energia, em alguns peixes da Amazônia em comparação com os niveis recomendados.

Os peixes com as melhores razões zinco/ energia são os menos gordos. É interessante notar que os peixes gordos são muitas vezes considerados como "reimosos", com pouco uso pela população e restrito especialmente a pessoas doentes ou em estados especiais de gravidez ou lactação.

Em relação aos outros alimentos ricos em proteína, como carnes, vísceras, queijos etc., os peixes em geral apresentam menores teores de zinco. Se os outros alimentos que compõem a base da dieta fossem ricos em zinco, como arroz integral, trigo integral, feijão, leite, verduras, legumes, etc. a dieta baseada em peixe ainda poderia ser suficiente quanto ao zinco. Se os outros alimentos que formam a base da dieta, forem pobres em zinco, como farinha de mandioca, batatas, açúcar, arroz po- 
iido, pão comum, mecarrão, óleos e gorduras, como é o caso de Manaus, a dieta não vai satisfazer às recomendações para zinco.

As bases científicas para as recomendações diárias para zinco ainda não estão bem fundamentadas (Food and Nutrition Board, 1980) o alguns países acham que as recomendações americanas são aitas (Department of National Health and Welfare, 1976). Considerando que, nos trópicos, as perdas no suor são maiores de que nos c!imas temperados, acreditamos que as recomendações para zinco dos Estados Unidos não são altas para os trópicos.

Considerando a importância de zinco no metabolismo dos ácidos nucléicos, no crescimento, na divisão de células, na formação de algumas enzimas, nos processos imunológi$\cos$ e reprodutores, consideramcs que existe a possibilidade de que uma dieta baixa em zin. co possa interferir nestes processos. Ainda faltam estudos que comprovem que os baixos níveis de ingesta de zinco encontrados $\mathrm{cm} \mathrm{Ma}$ naus sejam prejudiciais ao ser humano. Porém a lógica não nos leva a crer çue o manauara está sendo prejudicado.

\section{Conclusões}

Dos peixes da Amazônia, analisados neste estudo, os herbívoros e/ou onívoros apresentaram altos teores de energia, face aos altos conteúdos de gordura neles encontrados. Nestes peixes, as concentrações de gordura provavelmente mudam bastante, durante o ano em função da época da desova.

Os peixes carnívoros apresentaram baixo teor de gordura. As razões proteína/energia eram o dobro dos niveis recomendados em todos os peixes, apontando-os como excelentes fontes protéicas. As razões zinco/caloria nos peixes gordos eram abaixo dos níveis recomendados e somente os peixes magros tinham altas razões zinco/energia. De um modo geral, os peixes são mais pobres em zinco dc que outros alimentos proteícos, como carne de boi, queijo e feijão. No entanto, é preciso maiores estudos para definir se os baixos níveis de ingesta de zinco, encontrados em populares com base alimentar em peixe, como é o caso de Manaus, são associados com deficiências subclínicas de zinco.

\section{AGRADECIMENTOS}

Este trabalho foi realizado com recursos financeiros do Conselho Nacional de Desenvolvimento Científico e Tecnoiógico (CNPq) e da Secretaria de Coperação Econômica e Técnica Internacional (SUBIN). Agradecemos à Srta. Vera Maria Ferreira da Silva pela ajuda na identificação e nomenclatura dos peixes, bem como pelos comentários e discussōes sobre o manuscrito.

\section{SUMMARY}

The eleven species of fish most consumed in Manaus in 1973-74 were analyzed for humidity, ash, protein, fat, energy and zinc. Carnivorous fish such as Tucunaré, Pirarucú and Pescada were found to be lean whereas Pacú, Sardinha, Curimatã, Matrinchã and Branquinha were found to be fatty. All of the fishes were high in protein, with protein energy ratios greatly in excess of the recommendations. Zinc energy ratios were only high in the lean, carnivorous fishes, which are the most expensive and sought after in the local market. The herbivorous, and omnivorous fishes, with high fat contents, had zinc energy ratios below recommended levels. The possible importance of these findings are discussed.

\section{REFERENCIAS BIBLIOGRAFICAS}

ARAÚJO LIMA, J.F.

1923 - Ligeira contribuiçăo ao estudo do problema alimentar das populações rurais do Amazonas. Bol. San., DNSP, 2: 21-24.

ARMITAGE, P.

1971 - Statistical methods in medical research. Oxford. Blackwell Scientific Publ. 804p.

DEPARTMENT OF NATIONAL HEALTH AND WELFARE 1976 - Dietary Standards for Canada. Otawa Supply and Services, Canada.

FOOD AND NUTRITION BOARD

1980 - Recommended dietary allowances. Washington, D.C. National Research Council, National Academy of Sciences, 140p.

HONDA, E.M.S.

1972 - Peixes encontrados nos mercados de Manaus. Acta Amazonica, 2 (3): 97-98. 
HORWITZ, W.

1975 - Association of Official Analytical Chemistry - A.O.A.C.

ISAAC, R.A. \& JOHNSON, W.C.

1975 - Collaborative study of wet and dry ashing for the elemental analysis of plant tissue by AAS. J.A.O.A.C., 58: 436-440.

OSIS, D.; KRAMER, L.; WIATROWSKI, E; SPENCER, H. 1972 - Dietary zinc intake in man. Am. J. Clin. Nutr., 25: 258-588.

\section{PERKIN \& ELMER}

1976 - Analytical methods for atomic absorption spectroscopy. Norwalk. The Perkin Elmer Corporation, Conn.

SHRIMPTON, R.

1980 - Studies on zinc nutrition in the Amazon Valley. (Tese de Doutoramento). Universidade de Londres, 326p.
SHRIMPTON, R. \& GIUGLIANO, R.

1979 - Consumo de alimentos e alguns nutrientes em Manaus, Amazonas, 1973-74. Acta Amazonica, 9 (1): 117-141.

SOLOMONS, N.W. \& SHRIMPTON, R.

1982 - "Zinc" in Tropical and Geographical Medicine. Warren \& Mahmoud eds. McGraw Hill, New York (no prelo).

STANSBY, M.E.

1961 - Proximate composition of fish, FAO International Conference on Fish in Nutrition, Paper n. R/II, 1, 14pg. FAO, Rome.

STOCK, A.L. \& WHEELER, E.F.

1972 - Evaluation of meals cooked by large-scale methods: a comparison of chemical analysis and calculation from food tables. Brit. J. Nutr., 27: 439-448.

(Aceito para publicação em 15/09/82) 